\title{
Influência de Variáveis Climáticas sobre a Incidência de Meningite e sua Distribuição Espacial no Município de Ponta Grossa - PR, 2001-2005
}

\section{Influence of Climatic Variables on the Incidence of Meningitis and its Space Distribution in the City of Ponta}

Grossa-PR, 200I-2005

\author{
Caroliny Stocco \\ Bacharel em Enfermagem, enfermeira da Vigilância Epidemioló- \\ gica e Controle de Doenças da Secretaria Municipal de Saúde de \\ Ponta Grossa. \\ Endereço: Av. Visconde de Taunay, 950, Ronda. CEP 84051-000 \\ Ponta Grossa, PR, Brasil \\ E-mail: carolinystoccoळhotmail.com \\ Maysa de Lima Leite \\ Doutora em Agronomia. Professora do Departamento de Biologia \\ Geral da Universidade Estadual de Ponta Grossa (UEPG), \\ Endereço: Av. Carlos Cavalcanti, 4748, CEP 84030-900, Ponta \\ Grossa, PR, Brasil. \\ E-mail: mleiteळuepg.br \\ Valéria Beatris Labiak \\ Bacharel em Enfermagem \\ Endereço: Rua Siriri, 536, Vila Real, CEP 84064-060, Ponta Grossa, \\ $P R$, Brasil. \\ E-mail: valeria_labiakळhotmail.com \\ Jorim Sousa das Virgens Filho \\ Doutor em Energia na Agricultura. Professor do Departamento \\ de Matemática e Estatística da Universidade Estadual de Ponta \\ Grossa (UEPG). \\ Endereço: Av. Carlos Cavalcanti, 4748, CEP 84030-900, Ponta \\ Grossa, PR, Brasil. \\ E-mail:jvirgensळuepg.br \\ Éderson Nascimento \\ Mestre em Gestão do Território. \\ Doutorando em Geografia pela Universidade Estadual de Campi- \\ nas, Instituto de Geociências. \\ Endereço: Rua João Pandiá Calógeras, 51, CEP 13083-870, Cam- \\ pinas, SP, Brasil. \\ E-mail: edersonnnळyahoo.com.br
}

\section{Resumo}

Os elementos climáticos têm destacada influência sobre a manifestação de muitas doenças nos seres humanos. Assim, o objetivo deste estudo foi avaliar a influência de variáveis climáticas locais sobre a incidência mensal de meningite no Município de Ponta Grossa, Paraná, no período de 2001 a 2005, assim como distribuir espacialmente sua ocorrência na área urbana. A amostra inicial foi composta de 401 casos notificados e confirmados de indivíduos residentes nesse município. Verificou-se forte correlação entre a incidência média mensal de meningite e as variáveis climáticas temperatura média do ar, precipitação pluviométrica e umidade relativa do ar na maioria dos meses. A distribuição espacial dos casos em estudo revelou maior concentração nas porções centro-oeste e centro-norte da cidade.

Palavras-chave: Meningite; Incidência; Variáveis climáticas; Espacialização. 


\section{Abstract}

Climatic elements have an important influence on the manifestation of many human diseases. The objective of this study was to evaluate the influence of local climate variables on the monthly incidence of meningitis in the city of Ponta Grossa, State of Paraná, in the period from 2001 to 2005 , and to spatially distribute its occurrence in the urban area. The initial sample was composed of 401 notified cases which were confirmed as being of resident citizens in this city. Strong correlation was verified between the average monthly incidence of meningitis and the following climate variables: mean air temperature, precipitation and relative humidity in most months. The spatial distribution of the cases under study showed higher concentration in the central-west and north-central portions of the city.

Keywords: Meningitis; Incidence; Climatic Variables; Spatial Distribution.

\section{Introdução}

A investigação do comportamento epidemiológico de um agravo proporciona subsídios fundamentais para a redução e a prevenção desses eventos. Assim, quanto maior o número de variáveis analisadas mais ampla será a investigação. Dentre essas variáveis, devem-se levar em consideração a relação entre o processo saúde-doença e as características geográficas do lugar onde as doenças se manifestam.

Os impactos das condições climáticas sobre a sociedade repercutem de diversas formas na condição de saúde humana (Mendonça, 200o). Algumas doenças infecciosas tendem a seguir um padrão sazonal em sua incidência, como é o caso da varicela, da meningite, das doenças respiratórias, entre outras enfermidades (Prefeitura do Município de São Paulo , 2006). Essas doenças podem ser induzidas pelo clima em épocas diferentes e demonstram em suas incidências correlações íntimas com as condições climáticas e com a estação do ano, afetando a resistência do corpo humano, influenciando o crescimento, a propagação e a difusão de alguns organismos patogênicos ou de seus hospedeiros. Os elementos do clima que afetam mais diretamente as funções fisiológicas do homem incluem radiação solar, temperatura, umidade do ar, além do vento e da pressão atmosférica (Ayoade, 1986).

No entanto, nem todas as influências climáticas sobre a saúde humana são danosas. Algumas condições climáticas favoráveis - ar fresco, temperatura amena, umidade e a radiação moderada, entre outras - podem proteger e auxiliar na recuperação do corpo humano, tendo assim valor terapêutico (Ayoade, 1986).

A meningite consiste em uma inflamação das meninges, membranas protetoras que envolvem o cérebro e a medula espinhal, e é uma dessas doenças que apresentam relação com as condições climáticas. A transmissão é de pessoa para pessoa, através das vias respiratórias ou por contato direto com as secreções do paciente (Smeltzer e Bare, 2006). Entre as várias etiologias de meningite, a meningite bacteriana é a principal responsável por complicações tardias, principalmente sequelas neurológicas, constituindo-se na maior causa de surdez pós-natal (Kesser e col., 1999). A meningite 
viral é mais frequente que a meningite bacteriana, porém menos grave (Massachusetts Department of Public Health, 2010).

No município de Ponta Grossa, entre os anos de 2001 a 2005, observou-se frequência significativa para letalidade das meningites nos anos de 2002 (17,24\%), 2004 e 2005 (ambos com 13,33\%), já que a frequência encontrada foi de duas a três vezes maior que nos anos de 2001 e 2003 (Labiak e col., 2007). Assim, o monitoramento das meningites em geral é indispensável para subsidiar a adoção de medidas de controle dos contatos em tempo hábil (Fundação de Medicina Tropical do Amazonas, 2005), minimizando as complicações tardias e óbitos.

Entre outras enfermidades, a meningite faz parte do grupo de doenças cuja notificação é compulsória, isto é, é obrigatória: as autoridades sanitárias têm de ser informadas, por profissionais de saúde ou qualquer cidadão, da ocorrência de casos ou de surto da doença, visando à adoção de medidas de intervenção pertinentes (Brasil , 2002a).

As doenças infecciosas são mais rapidamente difundidas entre a população durante a estação fria, devido, principalmente, ao agrupamento de pessoas em ambientes fechados (Smeltzer e Bare, 2006; Bricks, 2002), uma vez que na estação quente as pessoas realizam mais atividades externas. Embora as meningites aconteçam o ano inteiro, registra-se maior incidência de casos de meningites bacterianas no inverno; e de meningites virais no início da primavera com predominância no verão (Smeltzer e Bare, 2006).

A expressiva reincidência dessas doenças infecciosas na atualidade coloca algumas questões não somente às ciências médicas, em particular à epidemiologia, mas demanda a participação de outros campos do saber (Mendonça, 200o), como a climatologia e a geografia da saúde. A saúde pública e a ambiência estão intrinsecamente influenciadas pelos padrões de ocupação do espaço geográfico, bem como pela distribuição e difusão de doenças em presença do meio físico em que se desenvolvem, ou seja, o clima, a vegetação, a qualidade da água e a qualidade do ar. O sistema de informação se tornará mais expressivo e eficiente se contiver a distribuição espacial dos dados, tornando-se um Sistema de Informações Geográficas (SIGs) (Najar e Marques, 1998).
Os SIGs permitem a análise de determinado fenômeno com sua localização espacial, podendo ser um instrumento importante para o planejamento, monitoramento e controle de doenças (Medronho, 1995). Portanto, a utilização dessa ferramenta pela Vigilância Epidemiológica permitiria uma melhor compreensão da ocorrência de determinado agravo com sua localização espacial, ampliando as análises epidemiológicas.

Com base nesse entendimento, a abordagem desenvolvida neste estudo teve como objetivo avaliar a influência de variáveis climáticas locais sobre a incidência mensal de meningite no Município de Ponta Grossa, Paraná, no período de 2001 a 2005, bem como distribuir espacialmente sua ocorrência na área urbana, no período analisado.

A análise dos dados referentes às variáveis climáticas e dos coeficientes de incidência de meningite buscam revelar a possível relação entre eles, além de verificar os meses de maior incidência. A espacialização dos casos possibilita a análise da situação desse agravo em nível local, levando também em consideração as condições socioeconômicas da população.

\section{Metodologia}

O município de Ponta Grossa situa-se na mesorregião centro-oriental do Estado do Paraná, a 130 km da capital Curitiba (Figura A).

\section{Figura A - Localização do município e da área urbana de Ponta Grossa no Estado do Paraná.}

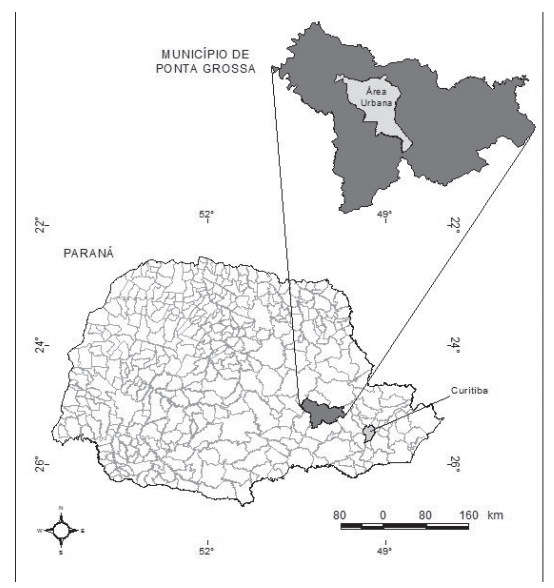

Fonte: Divisão Municipal do Brasil, IBGE, 2000 e Base Cartográfica - Prefeitura municipal de Ponta Grossa, 2005, modificada. 
Este estudo tem caráter epidemiológico ecológico, descritivo e quantitativo. Os dados climatológicos referentes ao período de investigação para o município de Ponta Grossa, foram obtidos junto à Estação Agrometeorológica de Ponta Grossa, situada no Parque Estadual de Vila Velha, com coordenadas geográficas de $25^{\circ} 13^{\prime}$ de latitude sul e $50^{\circ} \mathrm{O} 1$ ' de longitude oeste e 880 metros de altitude. As variáveis coletadas foram:

- temperatura média do ar $\left({ }^{\circ} \mathrm{C}\right)$;

- umidade relativa do ar (\%);

- precipitação pluviométrica (mm).

Os dados epidemiológicos foram levantados a partir das notificações e investigações de agravos de meningite e do banco de dados Sinan (Sistema de Informações de Agravos de Notificação) junto à Gerência de Vigilância Epidemiológica e Controle de Doenças do município de Ponta Grossa. Deste banco de dados, selecionaram-se as variáveis:

- dados pessoais do paciente (data da notificação e data dos primeiros sintomas);

- dados de residência (logradouro, vila e área rural ou urbana);

- conclusão (tipo de meningite).

A amostra inicial foi composta de 401 casos notificados e confirmados, entre 2001 e 2005, de indivíduos residentes no município de Ponta Grossa, no entanto, tomando como base a data dos primeiros sintomas, foram excluídos os casos com início de sintomas no ano de 2000, totalizando 398 casos.

Com relação à distribuição espacial da ocorrência de meningite, a amostra utilizada foi de 397 casos, tendo sido considerados somente os casos da área urbana, onde foi utilizado o software de geoprocessamento ArcGIS, versão 9.1.

As notificações e investigações dos casos de meningite foram avaliadas conjuntamente com os dados referentes às variáveis climáticas para a análise de suas possíveis interferências na incidência de meningite, bem como o estudo da sazonalidade dos casos.

Na obtenção dos modelos dos coeficientes mensais de incidência de meningite, foi utilizado o software STATISTICA. Para isso, empregou-se a técnica de análise de regressão, no âmbito multivariado linear, com a finalidade de se determinar o maior nível com o qual os elementos climatológicos avaliados foram capazes de evidenciar a correlação entre o clima e a incidência da patologia.

Os cálculos dos coeficientes de incidência mensal $\left(\mathrm{C} \cdot \mathrm{I}_{\mathrm{t}}\right.$ ), para o período em estudo, foram expressos por 10.000 habitantes. Considerou-se população exposta ao risco a população estimada pelo Instituto Brasileiro de Geografia e Estatística - IBGE, em 1 de abril de 2007, como sendo 306.351 habitantes (IBGE, 2007).

$\mathrm{O}$ coeficiente de incidência mensal médio esperado foi dado por:

$$
C \cdot \text { Iméd }_{t}=Y_{t} \text {, em que } Y_{t}
$$

é a média aritmética dos coeficientes de incidência calculados para todos os meses equivalentes, no período em estudo.

E o coeficiente de incidência mensal máximo esperado, para cada mês do ano, foi dado por:

$$
C \cdot \text { Imáx }_{t}=\mathrm{C} \cdot \text { Iméd }_{t}+Z_{\mathrm{t}} \text {, }
$$

onde $\mathrm{Z}$ corresponde ao número de desvios padrões que uma variável aleatória está afastada da média e $S_{t}$ refere-se ao desvio-padrão dos meses equivalentes, no período em estudo.

A pesquisa foi aprovada pelo Comitê de Ética em Pesquisa com Seres Humanos da Universidade Estadual de Ponta Grossa ${ }^{1}$.

\section{Resultados e Discussão}

Quanto ao número de notificações de casos de meningite confirmados, com base na data dos primeiros sintomas, foram registrados, a partir do banco de dados do Sinan, 165 casos em 2001, 57 casos em 2002, 71 casos em 2003, 46 casos em 2004 e 59 casos em 2005 .

Na Figura 1A, são apresentados os coeficientes mensais da incidência média de meningite. Observou-se que o mês de janeiro apresentou a maior

\footnotetext{
1 A pesquisa foi aprovada, em 15 de fevereiro de 2007, sob o parecer $n^{0}$ o6/2007 pelo Comitê de Ética em Pesquisa com Seres Humanos da UEPG. Os dados obtidos foram utilizados para fins exclusivos de pesquisa científica preservando-se a identidade dos sujeitos, de acordo com a Resolução n $196 / 96$ do Conselho Nacional de Saúde.
} 
incidência (0,53/10.00o habitantes), seguido pelos meses de fevereiro e setembro (o,37 e o,24/10.0oo habitantes, respectivamente).

Os meses de janeiro e fevereiro apresentaram temperaturas médias mais elevadas, precipitação intensa e umidade relativa do ar ligeiramente mais baixa que os meses de inverno (Figuras $1 B,{ }_{1} \mathrm{C}$ e 1D). A alta incidência média de meningite nos referidos meses poderia ser explicada, de acordo com os dados da Figura 2, devido ao aumento do número de casos de meningite viral.

A meningite viral é mais frequente que a meningite bacteriana, porém menos grave, sendo os enterovírus o grupo etiológico de maior incidência, encontrando-se na garganta e fezes de pessoas infectadas. Esses vírus têm maior possibilidade de serem disseminados devido às condições precárias de higiene ou por contato íntimo, entre membros de uma mesma família (Paula, 2003).

Conforme investigação de Paula (2003), no Paraná, entre 1992 e 2001, a incidência de meningite viral foi maior nos meses mais quentes do ano (novembro a janeiro). Outro estudo discute que a frequência de casos de meningite viral se eleva no final do verão e começo do outono (Brasil, 2002b). Em Minas Gerais, entre 1993 e 1997, este tipo de meningite teve sua maior ocorrência na primavera (Miranzi e col., 2003).

Vale ressaltar que agosto e novembro apresentaram as menores incidências médias de meningite, sendo os coeficientes de o,13 e 0,12/10.00o habitantes respectivamente (Figura 1A). No mês de setembro, o aumento da temperatura, a precipitação mais intensa e a umidade relativa do ar ligeiramente mais baixa possivelmente contribuíram para elevar a incidência nesse mês (Figuras 1B, 1C e 1D). Agosto foi o mês com a menor precipitação e umidade relativa do ar e temperatura mais amena (Figuras 1B, $1 \mathrm{C}$ e 1D). No entanto, nessa menor incidência, observou-se, conforme mostra a Figura 2, que a meningite meningocóccica teve aumento significativo no número de casos a partir desse mês.

Outros estudos salientam que o tipo de meningite causada pelo meningococo (bacteriana) ocorre durante todo o ano, sendo mais frequente nos meses frios, em decorrência do seu modo de transmissão, que se deve por contato direto de pessoa para pessoa, por via respiratória, através de gotículas e secreções da nasofaringe (Paula, 2003). A aglomeração de pessoas favorece a transmissão da doença que aparece em ondas epidêmicas, com intervalos variados (Brasil, 2002b).

Em novembro, o aumento da temperatura e a precipitação intensa não contribuíram para um aumento significativo da incidência, embora o oposto tenha sido observado nos meses de janeiro e fevereiro. Verificou-se, porém, que no mês de novembro o percentual de umidade relativa do ar foi inferior aos meses de janeiro e fevereiro, sugerindo-se que esse elemento climático possa ter sido um dos fatores relacionados com a baixa incidência encontrada (Figura 1).

Na Figura 3, observam-se os coeficientes de incidência esperados de meningite, para o município de Ponta Grossa-PR. A expressão "coeficiente de incidência mensal máximo esperado com 97,5\% de probabilidade" significa que para o futuro se espera, no mês correspondente, que $97,5 \%$ dos coeficientes de incidência sejam iguais ou menores que o referido (Rouquayrol e Almeida Filho, 2003). Como se pode observar, os maiores coeficientes de incidência máxima esperado neste estudo são para os meses de janeiro e fevereiro, decrescendo nos meses subsequentes (Figura 3).

A variação entre os valores do coeficiente de incidência média mensal e máxima esperada pode ser explicada devido à pequena ou à grande variação entre as incidências de um determinado mês entre os anos estudados. Assim, janeiro apresentou o maior intervalo entre a incidência média mensal e máxima esperada, uma vez que a incidência desse mês por ano variou de o,oo a 1,96/10.ooo habitantes, com média de 0,53/10.0oo habitantes. Vale ressaltar que a incidência de 1,96 foi encontrada somente no ano de 2001, que foi um ano atípico. Eentre 2002 e 2005, a variação observada foi pequena tendo sido verificados valores desse coeficiente desde o,oo até o,33. Para esse mês, a partir de 2006, o coeficiente de incidência máximo esperado seria de cerca de 2,11/10.0oo habitantes, se o valor verificado em 2001 fosse realmente um valor normal (Figura 3). Caso contrário, o coeficiente de incidência máximo esperado para o mês de janeiro, a partir de 2006, seria de o,45/10.0oo habitantes. 
Figura I - Variação média mensal de meningite (A), temperatura média do ar (B), precipitação pluviométrica (C) e umidade relativa do ar (D), Ponta Grossa-PR, 2001-2005

(IA) $2001-2005$

Coeficientes de incidência de meningite por 10.000 habitantes

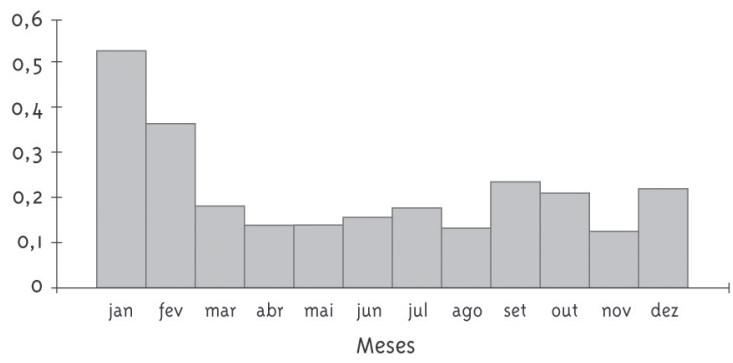

(IC) $2001-2005$

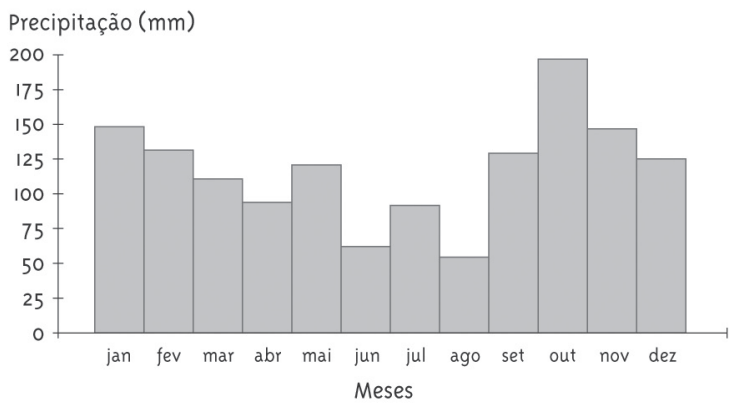

(IB) $2001-2005$

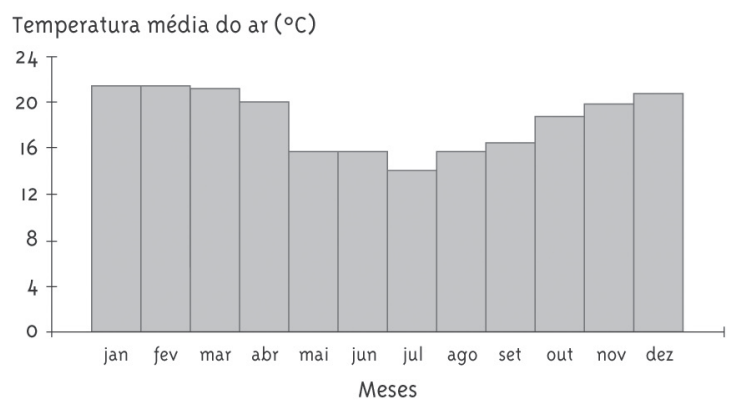

(ID) $2001-2005$

Umidade relativa do ar (\%)

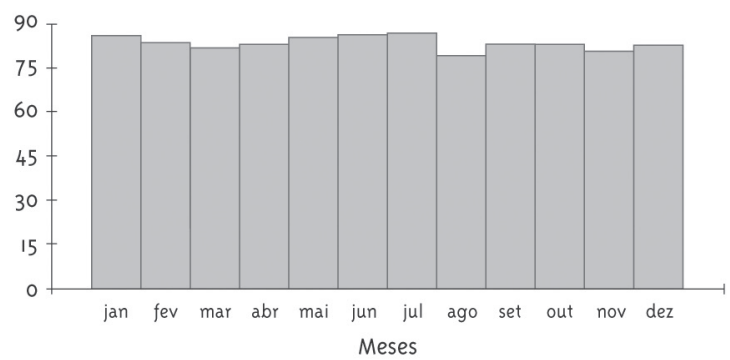

Fonte: Vigilância Epidemiológica de Controle de Doenças, 2007.

Simepar. 2007.

Figura 2 - Número de casos de meningite segundo a etiologia: MCC (Meningococcemia), MM (Meningite meningocóccica), MM+MCC (Meningite meningocóccica+meningococcemia), MB (Meningite bacteriana), MNE (Meningite não especificada), MV (Meningite viral), MOE (Meningite por outra etiologia), MH (Meningite por hemófilos), MP (Meningite por pneumococos), Ponta Grossa, PR, 2001-2005

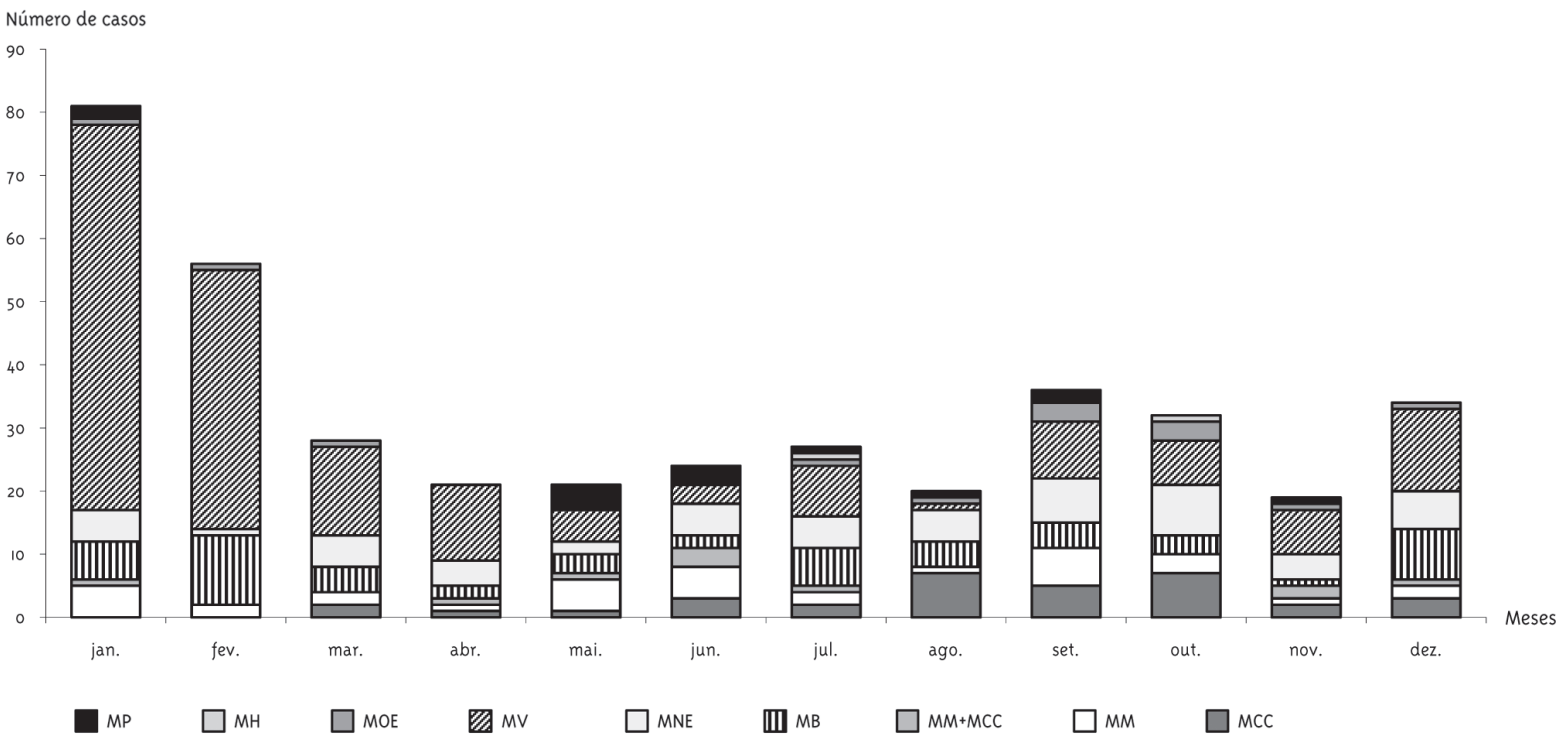

Fonte: Vigilância Epidemiológica de Controle de Doenças, 2007. 
O mês de novembro, que se manteve dentro da normalidade, apresentou a menor amplitude, pois o coeficiente de incidência mensal durante o período avaliado variou apenas de o,10 a o,16/10.0oo habitantes, com média de o,12/10.0oo habitantes. Portanto, para esse mês, a partir de 2006, o coeficiente de incidência máximo esperado é o,18/10.ooo habitantes (Figura 3).

Figura 3 - Coeficientes de incidência média mensal e máxima esperada de meningite, Ponta Grossa-PR, 2001-2005

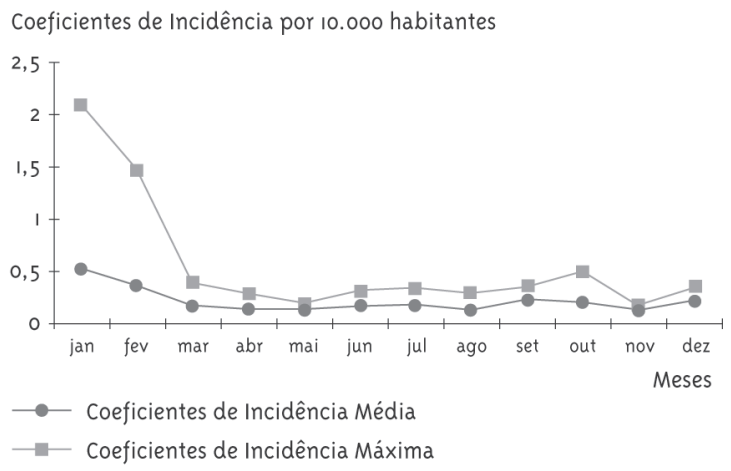

Fonte: Vigilância Epidemiológica de Controle de Doenças, 2007.
Na Tabela 1 são apresentadas as equações para estimativa dos coeficientes mensais de incidência de meningite em Ponta Grossa-PR, no período de 2001-2005. Observa-se que nessa localidade, na maioria dos meses, foram obtidos bons ajustes, considerando-se o coeficiente de Regressão $\left(\mathrm{R}^{2}\right)$, em que os modelos baseados nos elementos climáticos temperatura média do ar, umidade relativa do ar e precipitação pluviométrica, foram capazes de justificar amplamente os coeficientes mensais de incidência de meningite, sugerindo que as alterações nos valores médios desses elementos climáticos podem contribuir na ocorrência de casos da doença. Ajustes menos satisfatórios foram observados apenas nos meses de junho, julho e dezembro indicando que para esses meses os elementos climáticos analisados não foram suficientes para representar uma tendência local da enfermidade em questão. Além disso, os coeficientes correlação (R) observados, proporcionaram um eficiente meio de se verificar o alto grau de associação entre as variáveis climáticas avaliadas e o coeficiente de incidência na maioria dos meses.

Tabela I - Modelos de Regressão Linear e seus respectivos coeficientes de correlação $(R)$ e regressão $\left(R^{2}\right)$ para a estimativa dos Coeficientes Mensais de Incidência de Meningite no período de 2001-2005, na localidade de Ponta Grossa-PR

Legenda: $\mathrm{Cl}$ : Coeficiente de Incidência Média Mensal

TMED: Temperatura Média do Ar

UR: Umidade Relativa do Ar

PREC: Precipitação Pluviométrica

\begin{tabular}{|c|c|c|c|}
\hline & Modelo de regressão linear & R & $\mathrm{R}^{2}$ \\
\hline Janeiro & $\mathrm{Cl}=-24,86365+1,27622^{*} \mathrm{TMED}-0,02118^{*} \mathrm{UR}-0,00107^{*} \mathrm{PREC}$ & 0,8628 & 0,7445 \\
\hline Fevereiro & $\mathrm{Cl}=-2,54436-0,34526^{*} \mathrm{TMED}+0,11041^{*} \mathrm{UR}+0,00849^{*} \mathrm{PREC}$ & 0,8936 & 0,7986 \\
\hline Março & $C l=12,5800-0,20252^{*} T M E D-0,09745^{*} U R-0,00120^{*}$ PREC & 0,9920 & 0,9840 \\
\hline Abril & $\mathrm{Cl}=3,05885-0,10000^{*} T M E D-0,01108^{*} \mathrm{UR}+0,00006^{*}$ PREC & 0,9916 & 0,9832 \\
\hline Maio & $\mathrm{Cl}=0,84630+0,00090^{*}$ TMED $-0,01023^{*} \mathrm{UR}+0,00121^{*}$ PREC & 0,9269 & 0,8592 \\
\hline Junho & $\mathrm{Cl}=1,07303-0,04337^{*}$ TMED $-0,00200^{*}$ UR $-0,00103^{*}$ PREC & 0,4754 & 0,2260 \\
\hline Julho & $\mathrm{Cl}=-2,47141+0,11413^{*}$ TMED $+0,01391^{*}$ UR $-0,00185^{*}$ PREC & 0,7113 & 0,5059 \\
\hline Agosto & $\mathrm{Cl}=-0,26303-0,04278^{*} \mathrm{TMED}+0,01320^{*} \mathrm{UR}+0,00039^{*}$ PREC & 0,9287 & 0,8625 \\
\hline Setembro & $\mathrm{Cl}=1,28268-0,06518^{*} T M E D+0,00219^{*} \mathrm{UR}-0,00119^{*}$ PREC & 0,9882 & 0,9766 \\
\hline Outubro & $\mathrm{Cl}=1,22218+0,05902^{*}$ TMED $-0,02512^{*} \mathrm{UR}-0,00030^{*}$ PREC & 0,9492 & 0,9009 \\
\hline Novembro & $\mathrm{Cl}=8,29258+0,01770^{*}$ TMED $-0,12637^{*}$ UR $+0,01075^{*}$ PREC & 0,9896 & 0,9794 \\
\hline Dezembro & $\mathrm{Cl}=1,61725+0,01391^{*} T M E D-0,02304^{*} \mathrm{UR}+0,00172^{*}$ PREC & 0,4497 & 0,2022 \\
\hline
\end{tabular}

Fonte: Vigilância Epidemiológica de Controle de Doenças, 2007.

Simepar. 2007. 
Com relação à distribuição espacial dos casos, o estudo revelou que o maior número de casos ocorreu nas vilas Santa Paula (bairro Contorno) e Centro, seguidas pela Cipa (bairro Oficinas), Esplanada (bairro Boa Vista), Marina (bairro Uvaranas), Coronel Cláudio (bairro Uvaranas) e Parque Nossa Senhora das Graças (bairro Boa Vista), evidenciando uma concentração de casos nas porções centro-oeste e centro-norte da área urbana (Figura 4). As vilas supracitadas, que concentram o maior número de casos, localizam-se nos bairros mais populosos da cidade, sugerindo uma provável ligação entre os casos de meningite e o número populacional, levando-se em consideração a existência de aglomerados populacionais e a forma de transmissão da doença.

Na Figura 5 estão apresentados os coeficientes de incidência por bairro. É importante salientar que o Instituto Brasileiro de Geografia e Estatística não dispõe de dados populacionais por vilas, o que impossibilitou o cálculo do coeficiente de incidência. 0 maior coeficiente foi observado no bairro de Olarias

Figura 4 - Distribuição espacial dos casos de meningite segundo vilas, Ponta Grossa-PR, 200I-2005

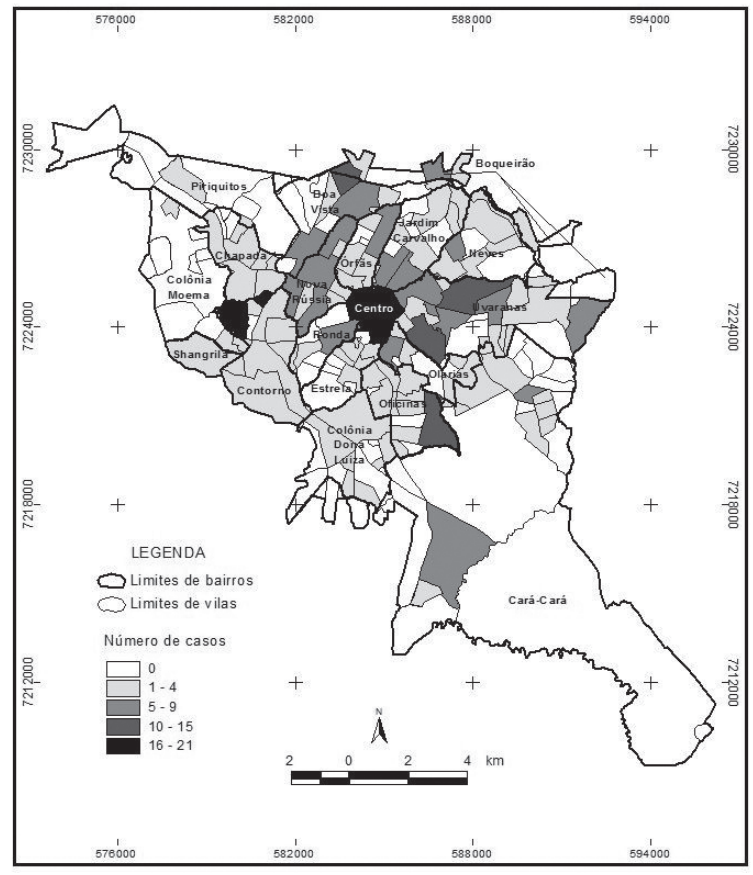

Fonte: Base cartográfica da Prefeitura Municipal de Ponta Grossa-PR, 2005, modificada.

Instituto Brasileiro de Geografia e Estatística - IBGE. Censo demográfico 2000. Gerência de Vigilância Epidemiológica e Controle de Doenças do município de Ponta Grossa-PR. Sinan. (23,79/10.0oo habitantes), seguido pelos bairros Jardim Carvalho (20,46/10.ooo habitantes), Uvaranas (19,11/10.0oo habitantes) e Contorno (19,05/10.0oo habitantes). Ao analisar esses coeficientes, observou-se que os bairros Contorno e Uvaranas, além de apresentarem alta incidência também, possuem vilas que apresentaram elevado número de casos. No entanto, o fato de outras vilas citadas terem tido alto número de casos e seus respectivos bairros não poderia estar relacionado ao fato de esse número ter se distribuído entre a população.

As condições socioeconômicas da população oferecem uma fonte valiosa para a pesquisa na área da saúde, em especial para a área epidemiológica (Najar e Marques, 1998).

A questão ambiental e de saneamento básico é outra parte integrante de qualquer trabalho que verse sobre saúde pública, sendo uma questão imprescindível a avaliação do nível de bem-estar de que dispõe a população da região avaliada (Najar e Marques, 1998).

Figura 5 - Coeficiente de incidência de meningite, segundo os bairros do município de Ponta Grossa-PR, 2001-2005

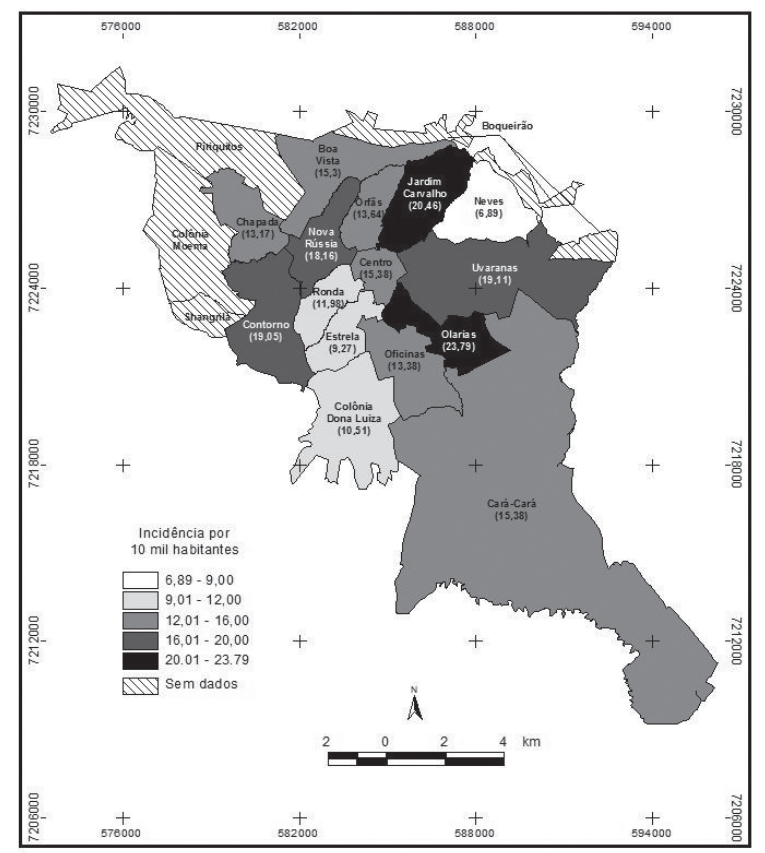

Fonte: Base cartográfica da Prefeitura Municipal de Ponta Grossa-PR, 2005, modificada.

Instituto Brasileiro de Geografia e Estatística - IBGE. Censo demográfico 2000. Gerência de Vigilância Epidemiológica e Controle de Doenças do município de Ponta Grossa-PR. Sinan. 
Na Figura 6 estão apresentados os percentuais de domicílios particulares permanentes sem abastecimento de água proveniente de rede geral por bairro. Observou-se que o maior percentual encontrado foi no bairro Contorno (10,44\%), seguido pelos bairros Chapada (5,67\%) e Boa Vista (4,04\%). Vale ressaltar que o bairro Contorno além de apresentar uma vila com o maior número de casos de meningite, também apresentou elevado coeficiente de incidência. Embora o bairro Boa Vista não tenha apresentado um elevado coeficiente de incidência, apresentou vilas com alto número de casos. A variável abastecimento de água foi um dos fatores avaliados, dentre outras variáveis que podem estar relacionadas com a ocorrência de agravos de saúde pública, como, por exemplo, a questão socioeconômica e a falta de saneamento básico.

Figura 6 - Domicílios particulares permanentes sem abastecimento de água proveniente de rede geral, segundo os bairros do município de Ponta Grossa-PR, 2000

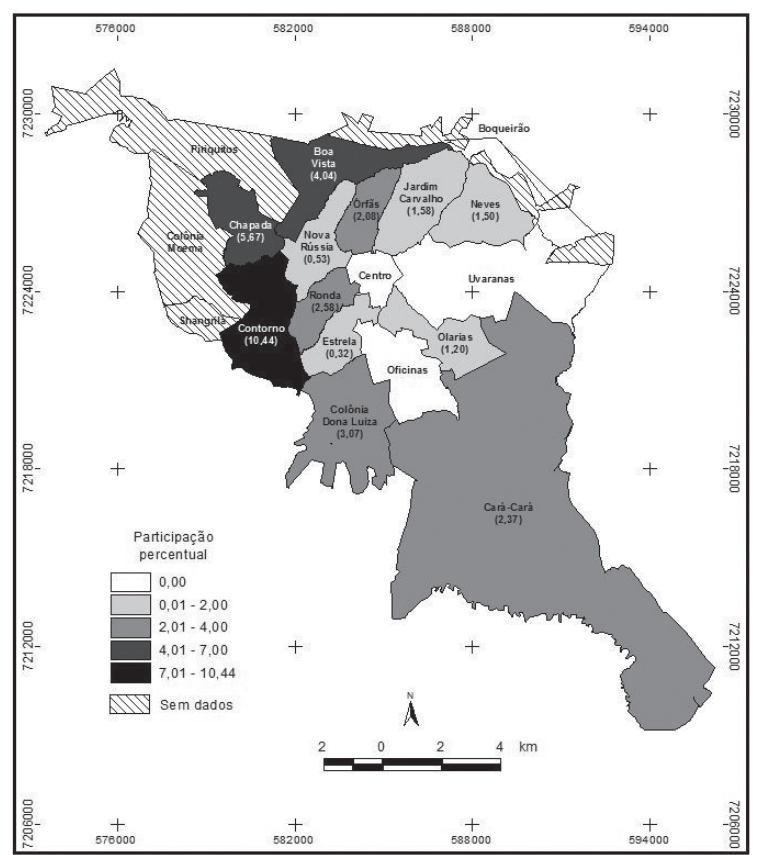

Fonte: Base cartográfica da Prefeitura Municipal de Ponta Grossa-PR, 2005, modificada.

Instituto Brasileiro de Geografia e Estatística - IBGE. Censo demográfico 2000.

Vale ressaltar que, na ficha de notificação e investigação de agravos não consta o item "rendimento", impossibilitando a realização da associação dessa variável com a ocorrência de meningite. Assim, sugere-se a inclusão do referido item na ficha de notificação e investigação de agravos para que seja possível efetuar a associação e a análise da questão socioeconômica com a ocorrência de meningite.

O uso de Sistemas de Informação na Epidemiologia pode contribuir para ações de prevenção e controle de doenças, possibilitando a análise da situação de saúde em nível local, considerando as condições de vida da população, na determinação do processo saúde-doença (Medronho, 1995).

Além disso, permitem que as autoridades públicas tenham uma visão espacial mais exata e abrangente das consequências advindas dos investimentos no gerenciamento do meio ambiente e da saúde pública. Torna-lhes possível rever e simular situações, analisar o resultado de tendências ou antecipar os prováveis resultados de decisões planejadas, comparando planos alternativos e refazendo a análise para cada alternativa proposta, em um tempo muito curto. (Najar e Marques, 1998).

\section{Considerações Finais}

Após a análise da associação dos dados referentes às variáveis climáticas e dos coeficientes de incidência, bem como a espacialização dos casos, conclui-se que:

- Foi observada uma forte correlação entre a incidência média mensal de meningite e as variáveis climáticas temperatura média do ar, precipitação pluviométrica e umidade relativa do ar na maioria dos meses, demonstrados através dos coeficientes de regressão e correlação.

- A distribuição espacial revelou maior concentração de casos nas porções centro-oeste e centro-norte da cidade, locais que também apresentaram alto índice de domicílios sem abastecimento de água. Isso demonstra que a distribuição dos casos também pode estar associada com fatores socioeconômicos, porém a variável "abastecimento de água" foi apenas uma das analisadas.

\section{Agradecimentos}

Agradecemos ao Instituto Tecnológico Simepar pelo fornecimento dos dados climatológicos e a Gerência de Vigilância Epidemiológica e Controle de Doencas pela colaboração no acesso às fichas de notificações e investigações de doenças sobre meningite e ao 
banco de dados Sinan, em especial à Gerente Lídia Dalgallo Zarpellon.

\section{Referências}

AYOADE, J. O. O clima e o homem. In:

Introdução à climatologia para os trópicos. São

Paulo: Difle, 1986. p. 289-291.

BRASIL. Ministério da Saúde. Doenças. Secretaria de Vigilância em Saúde. In: Guia de

Vigilância Epidemiológica. 5. ed. Brasília, DF:

FUNASA, 2002a. v. 1, p. 26-27.

BRASIL. Ministério da Saúde. Secretaria de Vigilância em Saúde. Doenças. In: . Guia de Vigilância Epidemiológica. 5. ed. Brasília, DF: FUNASA, 2002b. v. 2, p. 598-63o.

BRICKS, L. F. Doenças meningocócicas - morbidade e epidemiologia nos últimos 20 anos: revisão.

Pediatria, São Paulo, v. 24, n. 3/4, p. 122-131, 2002.

FUNDAÇÃO DE MEDICINA TROPICAL DO

AMAZONAS. Meningites diagnosticadas e notificadas na FMTAM no período de 2004 e $1^{0}$ semestre / 2005. Informe Epidemiológico, Manaus, n. 2, abr./jun. 2005. Disponível em: <http://www. fmt.am.gov.br/informe/o02-2005meningite.pdf>. Acesso em: 9 fev. 2010.

IBGE - INSTITUTO BRASILEIRO DE GEOGRAFIA E ESTATÍSTICA. Contagem da população 2007: população residente em $1^{0}$ de abril de 2007 , segundo os municípios: Paraná. Rio de Janeiro, 2007. Disponível em: <http://www.ibge.gov.br/ home/estatistica/populacao/contagem2007/ PR.pdf >. Acesso em: 8 fev. 2010.

KESSER, B. W. et al. Time course of hearing loss in an animal model of pneumococcal meningitis. Otolaryngol Head Neck Surg, v. 120, p. 628-637, 1999.

LABIAK, V. B. et al. Aspectos epidemiológicos dos casos de meningite notificados no município de Ponta Grossa - PR, 2001-2005. Cogitare Enfermagem, Curitiba, v. 12, n. 3, p. 310, 2007.

\section{MASSACHUSETTS DEPARTMENT OF PUBLIC} HEALTH. Meningite. Informativo de Saúde Pública, Boston, ago. 2005. Disponível em: <http:// www.mass.gov/Eeohhs2/docs/dph/cdc/factsheets/ meningitis_pt.pdf >. Acesso em: 9 fev. 2010.
MEDRONHO, R. A. Geoprocessamento e saúde: uma nova abordagem do espaço no processo saúde-doença. Rio de Janeiro: Fiocruz, 1995. MENDONÇA, F. Aspectos da interação climaambiente-saúde humana: da relação sociedadenatureza à (in)sustentabilidade ambiental. $R A^{\prime} E G A$, Curitiba, n. 4, p. 85-99, 2000.

MIRANZI, S. S. C.; CAMACHO, L. A. B.; VALENTE, J. G. Haemophilus influenzae tipo b: situação epidemiológica no Estado de Minas Gerais, Brasil, 1993 a 1997. Cadernos de Saúde Pública, Rio de Janeiro, v. 19, n. 5, p. 1273, 2003.

NAJAR, A. L; MARQUES, E. C. (Org.). Saúde e espaço: estudos metodológicos e técnicas de análise. Rio de Janeiro: Fiocruz, 1998.

PAULA, E. V. Evolução temporo-espacial das meningites no Estado do Paraná ao longo do século XX: abordagem climatológica. In: SIMPÓSIO BRASILEIRO DE SENSORIAMENTO REMOTO, 11., 2003, Belo Horizonte. Anais..., Belo Horizonte, 2003. p. 1415-1422.

PREFEITURA DO MUNICÍPIO DE SÃO PAULO. Secretaria Municipal da Saúde. Vigilância em Saúde. Núcleo Municipal de Controle de Infecção Hospitalar. Doenças de notificação compulsória e as comissões de controle de infecção hospitalar. São Paulo, 2006. Disponível em: <http://www. prefeitura.sp.gov.br/cidade/secretarias/upload/ DOENCAS_DE_NOTIFICACAO_COMPULSORIA_E_ AS_COMISSOES_DE_CONTROLE_DE_INFECCAO_ HOSPITALAR_1254771022.pdf>. Acesso em: 9 fev. 2010.

ROUQUAYROL, M. Z.; ALMEIDA FILHO, N. Epidemiologia e saúde. 6. ed. Rio de Janeiro: MEDSI: Guanabara Koogan, 2003.

SMELTZER, S. C.; BARE, B. G. Tratamento de pacientes com infecções neurológicas, distúrbios auto-imunes e neuropatias. In: Tratado de enfermagem médico-cirúrgica. 10. ed. Rio de Janeiro: Guanabara Koogan, 2006. v. 4, p. 2055-2081.

Recebido em: 02/09/2008

Reapresentado em: 08/08/2009

Aprovado em: 30/09/2009 